\title{
EVALUASI DAN PENINGKATAN PENGELOLAAN SKYWALK SEBAGAI DESTINASI WISATA (STUDI KASUS: KAWASAN CIHAMPELAS, KOTA BANDUNG, JAWA BARAT)
}

\author{
Maudy Fena Namiraa), B. (rwan Wipranata ${ }^{2)}$, Liong Ju Tjung ${ }^{3)}$ \\ 1)Program Studi S1 PWK, Fakultas Teknik, Universitas Tarumanagara, maudyfena@gmail.com \\ 2) Program Studi S1 PWK, Fakultas Teknik, Universitas Tarumanagara, irwan_wipranata@yahoo.co.uk \\ 3) Program Studi S1 PWK, Fakultas Teknik, Universitas Tarumanagara, jt.liong@pps.untar.ac
}

Masuk: 03-08-2021, revisi: 01-09-2021, diterima untuk diterbitkan: 23-10-2021

\begin{abstract}
Abstrak
Wisata yang dilakukan pada skywalk merupakan salah satu fenomena perwujudan ruang publik rekreasi pada kota. Kota Bandung yang sudah jenuh akibat tidak sebandingnya pergerakan wisatawan dengan persediaan jalan menghadirkan pembangunan proyek skywalk untuk mengatasi masalah ini. Skywalk Teras Cihampelas adalah salah satunya, merupakan jalur pejalan kaki layang pertama di Indonesia dan dengan cepat menjadi destinasi wisata pilihan di Kota Bandung. Skywalk Teras Cihampelas juga menjadi contoh bagi wilayah lainnya sebagai motivasi pengadaan jalur pejalan kaki sebagai ruang publik rekreasi dan wisata. Namun tidak lama sejak peresmiannya, banyak masalah yang muncul seperti tindak kriminal, kerusakan fasilitas dan kekumuhan akibat pengadaan terpal yang kelamaan membuat skywalk sepi pengunjung. Banyak pihak menyayangkan kejadian ini dan khawatir bahwa proyek skywalk yang masih panjang berpotensi tidak sesuai dengan tujuan awalnya dan gagal. Tujuan dilakukannya penelitian ini adalah mengevaluasi hambatan dan meningkatkan pengelolaan skywalk yang berorientasi pada pariwisata efektif. Metode yang dilakukan adalah skoring dari standar jalur pejalan kaki dan benchmarking/mengacu pada best practise untuk mengidentifikasi hal-hal yang perlu perbaikan dan mempelajari potensi peningkatan komponen wisata. Berdasarkan hasil penelitian, masalah utama yang menjadi penghambat adalah buruknya manajemen pengelolaan terutama dari segi keuangan, promosi, sumber daya manusia serta sulitnya birokrasi pengajuan perbaikan. Perubahan dapat dilakukan dengan menyatukan pendapat antar pengelola, membenahi manajemen dan menghadirkan inovasi atau atraksi baru dengan mencontoh apa yang sudah dilakukan pada skywalk lainnya.
\end{abstract}

Kata kunci: jalur pejalan kaki ; pariwisata ; skywalk

\begin{abstract}
Tourism on a skywalk is one of the phenomena of embodiment of recreational public spaces in the city. The city of Bandung, which has difficulty accomodating tourist movements due to the disporpotionate growth of tourists with road supplies, has implemented a skywalk project to overcome this problem. Skywalk Teras Cihampelas is the first elevated pedestrian path in Indonesia and quickly becoming the preffered tourist destination in Bandung. Skywalk Teras Cihampelas also become an example for other areas as a motivation for procuring pedestrian paths as public spaces and tourism destination. However, not long after its opening, many problems arose such as crime, damage to facilities and slums due to the procurement of tarpaulins which gradually made the skywalk lost its visitors. Many people regret this phenomenon and worry that the skywalk project has the potential to not meet its original goals and fail. The purpose of this research is to evaluate the barriers and improve the managements of skywalk that are oriented towards effective tourism. The method used are scoring based on pedestrian path standards and benchmarking to identify and study things that need improvement. Based on the result of the study, the main problem that became the obstacle was the poor management, especially in terms of finance, promotion, human resources and the difficulty of the bureaucracy in filing for improvement. Changes can be made by uniting opinions between the managements and preseting new innovations or attraction by following good examples from other skywalks.
\end{abstract}

Keywords: pedestrian path ; skywalk ; tourism 


\section{PENDAHULUAN}

\section{Latar Belakang}

Kota Bandung merupakan salah satu daerah tujuan wisata utama di Indonesia baik bagi wisatawan mancanegara maupun lokal. Kota Bandung terkenal bukan hanya karena pemandangan alamnya yang indah, tetapi juga banyak peninggalan sejarah, kuliner unik, pusat pertokoan fashion dan lainnya yang menjadi daya tarik urban tourism. Kawasan Cihampelas merupakan salah satu lokasi wisata utama di Kota Bandung yang sudah terkenal sejak tahun 90-an sebagai shopping street sentra penjualan jeans dan tekstil serta merupakan Kawasan Pariwisata Belanja dan Warisan Budaya menurut Peraturan Daerah Kota Bandung No. 1 Tahun 2013 tentang RIPPDA 2012 - 2025. Banyak juga pertokoan lainnya yang mewarkan kuliner dan berkumpulnya Pedagang Kaki Lima (PKL). Pertumbuhan kunjungan wisatawan pada Jalan Cihampelas semakin lama semakin padat, dimana Jalan Cihampelas yang hanya memiliki luas sebesar 7-meter tidak kuat menampung pergerakan lalu lintas, PKL dan wisatawan sekaligus. Untuk menyelesaikan permasalahan ini, Pemerintah Kota Bandung melakukan pembangunan Skywalk Teras Cihampelas sebagai jalur pejalan kaki wisatawan Kawasan Cihampelas, pergerakan antar pusat kegiatan dan tempat relokasi PKL yang sebelumnya berdagang di sisi jalan. Pembangunan skywalk ini dimuat pada Peraturan Daerah Kota Bandung No. 3 Tahun 2014 tentang Rencana Pembangunan Jangka Menengah (RPJMD) Kota Bandung pada bagian pembangunan infrastruktur.

Skywalk Teras Cihampelas memiliki lebar 9 meter, panjang 450-meter dan tinggi 4,6-meter dari permukaan Jalan Cihampelas. Skywalk ini adalah sebagian kecil dari proyek skywalk yang akan menghubungkan Jalan Cihampelas - Jembatan Pasupati - Balubur Town Square - Jalan Taman Sari dan rencana Park and Ride di Jalan Gelap Nyawang. Pembangunan skywalk dilakukan oleh Pemerintah Kota Bandung bekerjasama dengan Dinas Pekerjaan Umum Kota Bandung dan PT Likatama Graha Mandiri, diresmikan pada tahun 2017 dan dengan cepat menjadi salah satu 10 besar destinasi wisata pilihan se-Indonesia pada pertengahan tahun dan mendapat Juara 3 Anugerah Pesona Indonesia dari Kemeterian Pariwisata pada akhir tahun (jabarprov.go.id, 2017).

Namun berbagai permasalahan kemudian muncul pada Skywalk Teras Cihampelas, bahkan saat baru setahun setelah diresmikan. Fasilitas yang ada mulai tidak terawat, muncul keluhan ketidakadaan fasilitas peneduh karena banyak yang menganggap pohon-pohon tidak dapat melindungi dari cuaca, terjadinya tindak kriminalitas seperti pencurian penerangan (lampu), APAR dan barang dagangan PKL (Permana, 2019). Kemudian para PKL mulai memasang terpal untuk kios-kiosnya dan berpotensi membuat skywalk kumuh, minimnya promosi skywalk dan masih banyaknya PKL yang berdagang di bawah skywalk membuat kondisi menjadi sepi karena wisatawan malas dan tidak tertarik untuk naik, terlebih dengan tidak adanya konektivitas skywalk terhadap pertokoan di Kawasan Cihampelas.

Evaluasi pengelolaan dari Skywalk Teras Cihampelas penting untuk dilakukan agar dapat mengidentifikasi, memberikan masukkan tahapan penyelesaian dan peningkatan pengelolaan skywalk secara struktural dengan menyelesaikan hambatan yang ada terlebih dahulu. Apabila tidak terjadi pembenahan, skywalk nantinya akan semakin ditinggalkan dan kehilangan fungsi awalnya sebagai pedestrian dan destinasi pariwisata. Penelitian akan ditekankan dengan mengevaluasi pengelolaan komponen wisata, perbandingan terhadap standar pedestrian dan mempelajari bagaimana skywalk lain dapat berhasil menjadi destinasi wisata sehingga nantinya ditemukan rekomendasi terbaik untuk peningkatan pengelolaan yang efektif sebagai destinasi wisata Kota Bandung.

\section{Rumusan Permasalahan}

Berbagai permasalahan yang muncul pada Skywalk Teras Cihampelas menjadi perhatian banyak orang, terutama masalah mengenai sepinya lokasi wisata skywalk dan kurangnya upaya pemeliharaan fasilitas. Apabila tidak terjadi pembenahan, terdapat kekhawatiran mengenai skywalk 
yang kehilangan fungsinya sebagai pedestrian, kegiatan komersial dan ikon pariwisata. Beberapa upaya telah dilakukan oleh Pemerintah Kota Bandung dan Badan Pengelola Teras Cihampelas (BPTC) untuk melakukan reaktivasi seperti pengecatan kursi dan penambahan stage, namun beberapa pihak menganggap upaya ini tergolong gagal karena tidak tepat sasaran, tidak memperhatikan permasalahan yang ada di lapangan, minim usaha peningkatan daya tarik wisata, bahkan tidak adanya kerjasama yang baik antar Forum Satuan Tugas Pengelola yang mengakibatkan skywalk masih sepi dari pengunjung. Dibutuhkan evaluasi untuk menyesuaikan kembali skywalk terhadap fungsi awalnya sehingga nantinya ditemukan rekomendasi terbaik untuk peningkatan pengelolaan yang efektif dan berjangka panjang sebagai destinasi wisata Kota Bandung.

\section{Tujuan}

Penelitian ini dilakukan dengan maksud untuk mengevaluasi permasalahan yang ada dan mengidentifikasi cara atau memberikan usulan untuk peningkatan pengelolaan sebagai destinasi wisata pada Skywalk Teras Cihampelas. Maksud penelitian memiliki tujuan yang spesifik, yakni; 1) mengevaluasi hambatan dan menemukan potensi peningkatan aspek pariwisata, dan 2) mengetahui rekomendasi bagaimana meningkatkan pengelolaan yang berorientasi pada pariwisata efektif pada Skywalk Teras Cihampelas. Hal ini didasarkan agar usulan peningkatan pengelolaan pariwisata skywalk dapat tepat sasaran, terstruktur dan meningkatkan daya tarik untuk wisatawan.

\section{KAJIAN LITERATUR \\ Ruang Publik}

Ruang publik merupakan bagian dari ruang kota yang berfungsi sebagai penampung aktivitas manusia baik sosial maupun fungsional dan terletak di kawasan berintensitas kegiatan tinggi, dapat menyesuaikan dengan kebutuhan manusia dan dapat diakses siapapun tanpa ada diskriminasi latar belakang suatu masyarakat. Menurut Carr et al. (1992), ragam ruang publik kian banyak seiring berkembangnya zaman, mulai dari taman dengan berbagai skala (kota, regional, lingkungan), plaza, pasar, memorial park, pedestrian, jalan, square, sempadan sungai, ataupun ruang terbuka yang belum terbangun di lingkungan tempat tinggal. Suatu ruang kota yang dapat dikategorikan sebagai ruang publik harus memenuhi lima kebutuhan dasar yang mempengaruhi kepuasan dari penggunanya, yakni a) Kenyamanan. yang dapat diukur dengan kemudahan akses pencapaian yang terintegrasi dengan baik, kemudahan melakukan kegiatan dan kemudahan dalam berkomunikasi (secara internal maupun eksternal), b) Relaksasi, yakni pemberian ketenangan dari segi psikologis dan membuat pikiran menjadi lebih santai, c) Keterikatan pasif, yakni ruang dapat memberikan perasaan untuk datang kembali dari segi pemandangan, pertunjukkan atau lainnya, d) Keterikatan aktif, yakni ruang dapat memberikan pengalaman langsung atau interaksi sosial, dan e) Penemuan, yakni ruang dapat memberikan pengalaman yang menyenangkan.

\section{Jalur Pejalan Kaki}

Pengertian jalur pejalan kaki menurut Peraturan Meteri Pekerjaan Umum No. 03/PRT/M/2014 merupakan ruas pejalan kaki, baik yang terintergrasi maupun terpisah dengan jalan dengan peruntukkan untuk prasarana dan sarana pejalan kaki yang menghubungkan pusat-pusat kegiatan atau fasilitas pergantian moda. Jalur pejalan kaki juga tergolong ruang publik terjadinya interaksi sosial antar masyarakat. Jalur pejalan kaki memiliki ketentuan-ketentuan untuk kenyamanan penggunanya, dimana lebar minimal adalah 1,2 meter pada jalan lokal atau disesuaikan dengan intensitas penggunanya dengan lebar setidaknya $1,8 \mathrm{~m}$ pada intensitas rendah, memiliki perbedaan ketinggan dengan jalur kendaraan bermotor setidaknya $20 \mathrm{~cm}$ lebih tinggi, dan kemiringan maksimal $4 \%$, yang selebihnya harus digantikan dengan penyediaan anak tangga. Terdapat beberapa tipologi jalur pejalan kaki, yakni pedestrian sidewalk, promenade (jalur pejalan kaki di sisi air), jalur pejalan kaki di sisi bangunan, jalur pejalan kaki di bawah tanah, dan jalur pejalan kaki di atas permukaan tanah. Skywalk sendiri merupakan suatu media konektivitas pejalan kaki yang memiliki ketinggian tertentu di atas permukaan tanah, terdiri dari jembatan langit di atas jalan (Ciu, 2015). 
Jalur pejalan kaki juga harus didukung dengan penyediaan sarana jaringan pejalan kaki untuk mendukung fungsi sebagai penyebrangan, fungsi sebagai upaya pengadaan penghijauan dan fungsi sebagai ruang publik. Sarana jaringan pejalan kaki yang dapat diadakan adalah seperti lampu penerangan, tempat duduk, tempat sampah, papan informasi, halte. telepon umum dan lainnya. Penyediaan sarana jaringan pejalan kaki ini diatur dengan kriteria tertentu berdasarkan Peraturan Kementerian Pekerjaan Umum No. 03/PRT/M/2014 agar tidak mengganggu fungsi utamanya yang dipengaruhi oleh 6 faktor, yakni aksesibilitas (terutama untuk yang memiliki keterbatasan fisik), keselamatan, kenyamanan, keindahan, kemudahan (pengelihatan, pencapaian dan konektivitas) serta interaksi.

Selain itu, terdapat juga standar untuk elemen pejalan kaki agar dapat menciptakan jalur pejalan kaki yang baik berdasarkan Planning and Designing for Pedestrian Model Guidelines dari Community Design + Architecture, Inc. W-Trans untuk San Diego's Regional Planning Agency (SANDAG) pada tahun 2002. Meskipun model ini diperuntukkan bagi pedestrian di San Diego, namun model ini dapat diaplikasikan pada lokasi lain sebagai panduan perencanaan peningkatan suatu jalur pejalan kaki. Pada model ini dititik beratkan pada 6 elemen, yakni desain yang membagi zona antar jalur pejalan kaki dan zona lainnya, aksesibilitas yang memiliki konektivitas dan nyaman digunakan, kemudahan pencapaian dan penggunaan, keamanan, keindahan yang meningkatkan keakraban lingkungan dengan pejalan kaki serta elemen iklim, dimana dapat memberikan perlindungan dari cuaca.

\section{Pariwisata}

Pariwisata adalah suatu kegiatan perjalanan yang dilakukan seseorang/sekelompok orang yang hanya dilakukan untuk sementara waktu. Tujuan berwisata adalah untuk menikmati layanan dan fasilitas selama perjalanan yang dilakukan untuk kesenangan, bekerja, atau kepentingan lainnya. Terdapat beberapa komponen yang harus dimiliki oleh sebuah objek wisata menurut Fletcher et al. (2018) meliputi 1) aksesibilitas, yakni kemudahan pencapaian suatu objek wisata, 2) atraksi, yakni kegiatan kepariwisataan yang menarik wisatawan, 3) akomodasi, yakni jasa layanan penginapan, 4) amenitas, yakni prasarana dan fasilitas yang mendukung kegiatan wisata, 5) aktivitas, meliputi kegiatan atau event yang dapat dilakukan oleh wisatawan, dan 6) ancillary, yakni pengelola dari destinasi wisata.

\section{Evaluasi}

Evaluasi merupakan suatu pengumpulan informasi yang digunakan untuk menilai suatu objek evaluasi dengan perbandingan terhadap kriteria yang ditetapkan, dimana setelahnya diambil suatu keputusan agar dapat menentukan tindakan terhadap objek tersebut. Fungsi dari evaluasi adalah untuk memberikan informasi valid mengenai program dan capaian dari program, pemberian kritik untuk program tersebut dengan mengidentifikasi kepantasan dengan tujuan dan sasaran awal, serta untuk memberikan masukkan pemecahan permasalahan dengan melihat kemungkinan dilakukannya revisi, penggantian program ataupun penghentian program yang ada.

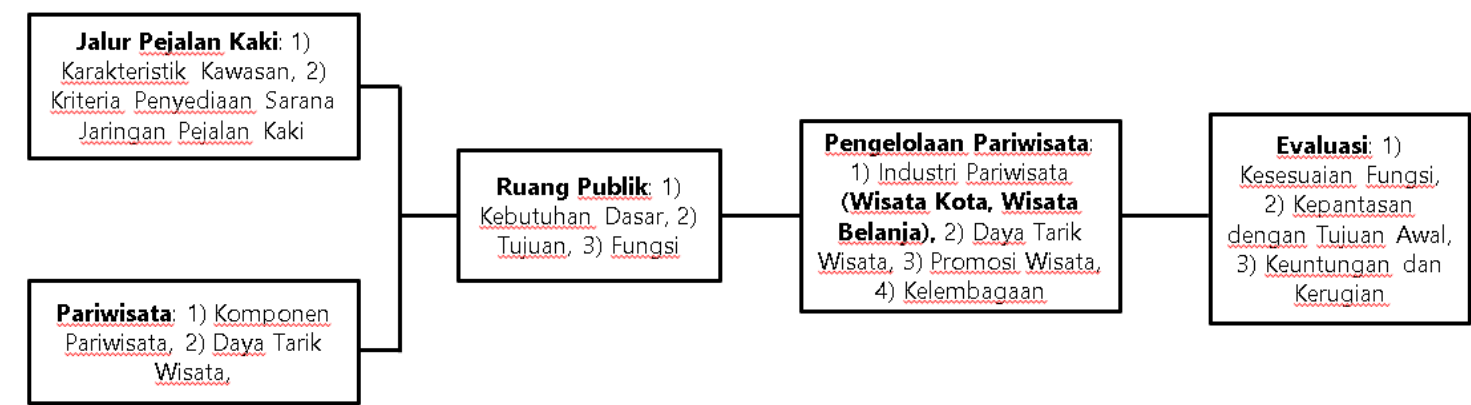

Gambar 1. Kerangka Teori

Sumber: Hasil Olahan Peneliti, 2020 


\section{METODE}

Lokasi penelitian meliputi Kawasan Jalan Cihampelas yang terletak di Kelurahan Cipaganti, Kecamatan Coblong, Kota Bandung. Tepatnya berada pada posisi 6 $53^{\prime} 44.2^{\prime \prime S} 107^{\circ} 36^{\prime} 14.1^{\prime \prime} \mathrm{E}$ dan berada di utara Jembatan Pasupati. Penelitian ini dilakukan dalam waktu \pm 10 bulan dengan menggunakan teknik pengumpulan data secara primer (survei lapangan, observasi, wawancara dan kuesioner melalui Google Form) serta secara sekunder (data dari pihak ketiga dari instansi terkait atau jurnal yang diambil secara daring melalui laman akademik). Teknik pengolahan data yang dilakukan terbagi atas beberapa analisis dengan data dan teknik pengolahan yang berbeda.
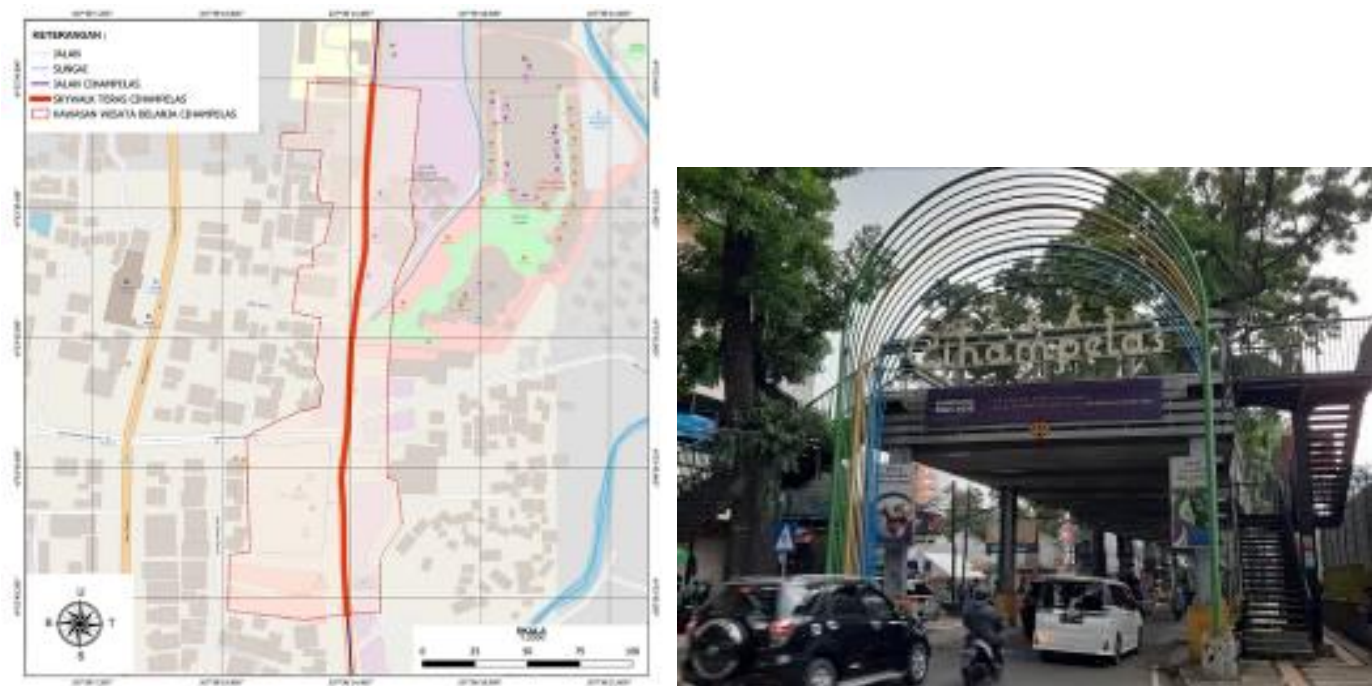

Gambar 2. Lokasi Penelitian

Sumber: Google Maps, Olahan Peneliti dan Dokumentasi Pribadi, 2020

Tabel 1. Metode Analisis Penelitian

\begin{tabular}{|c|c|c|c|}
\hline Analisis & Data & Teknik Pengolahan & Sumber \\
\hline $\begin{array}{l}\text { Analisis Evaluasi Pengelolaan } \\
\text { Komponen Wisata }\end{array}$ & $\begin{array}{l}\text { Aksesibilitas, aktivitas, } \\
\text { atraksi, akomodasi, } \\
\text { amenitas dan ancillary. }\end{array}$ & $\begin{array}{l}\text { Penilaian pengunjung } \\
\text { (skala likert), } \\
\text { deskripsi/penjelasan } \\
\text { observasi. }\end{array}$ & $\begin{array}{l}\text { Pengunjung berdasarkan } \\
\text { kuesioner Google Form } \\
\text { olahan peneliti, survei } \\
\text { lapangan }\end{array}$ \\
\hline $\begin{array}{l}\text { Analisis Evaluasi Kondisi } \\
\text { Terhadap Standar Jalur Pejalan } \\
\text { Kaki }\end{array}$ & $\begin{array}{l}\text { Aksesibilitas, } \\
\text { keselamatan, } \\
\text { kenyamanan, keindahan, } \\
\text { kemudahan dan } \\
\text { interaksi. }\end{array}$ & $\begin{array}{l}\text { Skoring dan penjelasan } \\
\text { deskriptif terhadap kriteria } \\
\text { yang sudah ditetapkan } \\
\text { berdasarkan standar jalur } \\
\text { pejalan kaki. }\end{array}$ & $\begin{array}{l}\text { Survei lapangan, ahli } \\
\text { akademisi, ahli dari } \\
\text { pemerintahan, Peraturan } \\
\text { Kementerian Pekerjaan } \\
\text { Umum No. 03/PRT/M/2014 } \\
\text { dan Pedestrian Model } \\
\text { Guidelines. }\end{array}$ \\
\hline Analisis Benchmarking & $\begin{array}{l}\text { Aksesibilitas,aktivitas, } \\
\text { atraksi, amenitas dan } \\
\text { ancillary. }\end{array}$ & $\begin{array}{l}\text { Perbandingan antar objek, } \\
\text { penjelasan deskriptif. }\end{array}$ & $\begin{array}{l}\text { Google Maps, Google Earth, } \\
\text { laman resmi objek } \\
\text { (thehighline.org, mvrdv.nl), } \\
\text { artikel berita, jurnal } \\
\text { akademisi lainnya }\end{array}$ \\
\hline
\end{tabular}

Sumber: Hasil Olahan Peneliti, 2020

\section{DISKUSI DAN HASIL}

\section{Analisis Evaluasi Pengelolaan Komponen Wisata}

Analisis ini dilakukan untuk mengetahui seberapa kuat komponen wisata dan potensi peningkatan objek wisata berdasarkan kondisi eksisting komponen wisata dan penilaian pengunjung yang dikumpulkan dengan kuesioner. Berikut adalah deskripsi kondisi eksisting komponen wisata yang ada pada Skywalk Teras Cihampelas. 
a. Aksesibilitas: Terdiri atas 12 area teras dengan 5 area keluar masuk. Area keluar-masuk memiliki alat sirkulasi berupa tangga + bordes + railing, ramp antar area teras dan lift namun dalam keadaan tidak aktif. Sirkulasi pada skywalk cenderung membentuk garis zig-zag karena adanya hambatan dari Kios PKL yang diletakkan tidak beraturan dan kadang bertumpuk.
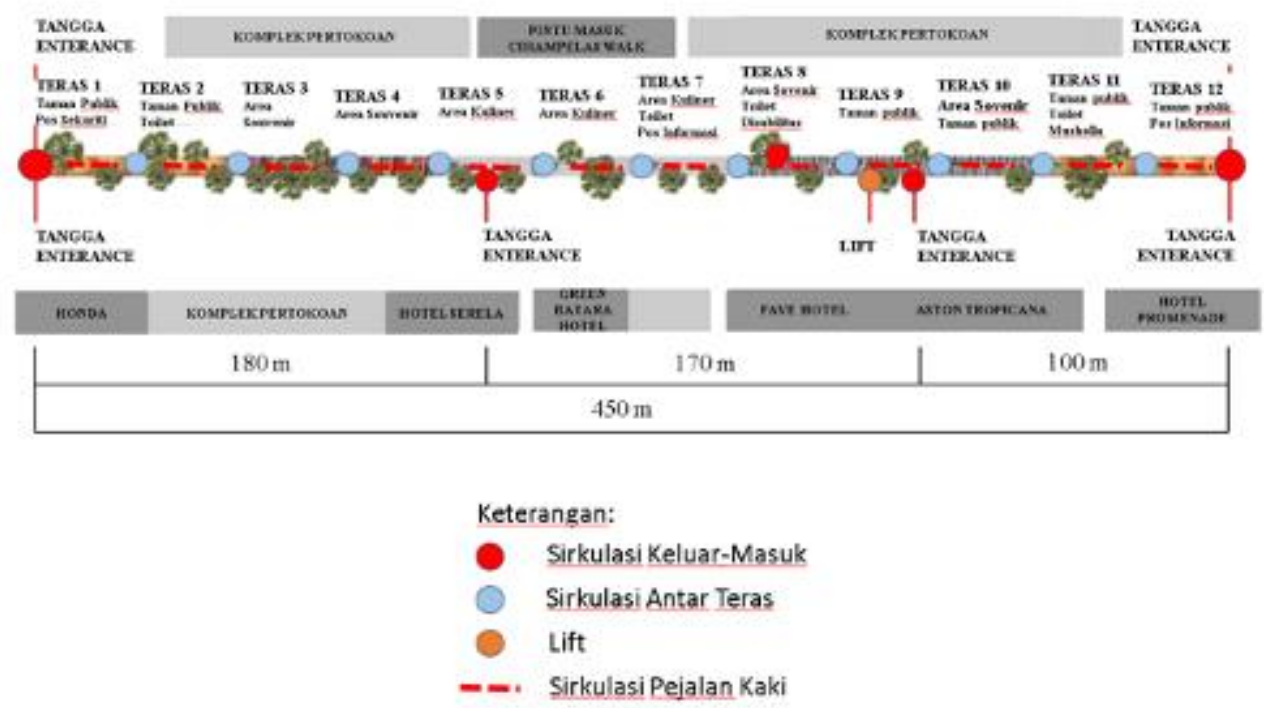

Gambar 3. Sirkulasi Pada Skywalk Teras Cihampelas

Sumber: BPTC dan Hasil Olahan Peneliti, 2020

b. Aktivitas dan Atraksi: Aktivitas dalam tempat wisata disimpulkan menjadi beberapa syarat yang harus dipenuhi, yakni something to see, something to do dan something to buy (Yoeti, 1996:177). Something to see dan something to do pada Skywalk Teras Cihampelas terdiri atas beberapa atraksi, yakni berupa tempat perbelanjaan seperti Kios PKL (special types of attraction), pengadaan spot foto dan pemandangan Kawasan Cihampelas (natural attraction), costume play dan pertunjukkan musik jalanan (special types of attraction). Namun beberapa atraksi seperti costume play dan pertunjukkan musik tidak terjadwal dan cenderung diadakan secara mendadak. Something to buy pada skywalk adalah wisatawan dapat membeli kerajinan lokal seperti baju, aksesoris, jeans serta kuliner dari berbagai wilayah dengan kategori murah sedang, yakni Rp $5.000-120.000,-$.
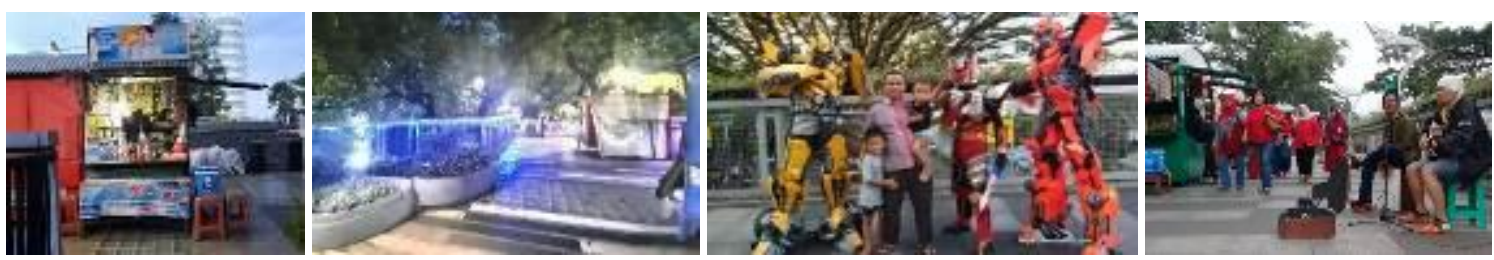

Gambar 4. Atraksi Pada Skywalk Teras Cihampelas

Sumber: Dokumentasi Pribadi, Google Photo dan Instagram @cihampelasteras, 2020

c. Akomodasi: Jasa layanan penginapan yang ada di dalam radius $500 \mathrm{~m}$ dari skywalk berjumlah 14 penginapan. Akomodasi ini terdiri atas 12 hotel dari bintang $1-4,1$ apartemen dan 1 wisma. Harga yang ditawarkan adalah sekitar Rp 150.000 - 1.000.000,- / malam. Wisatawan dapat memilih akomodasi sesuai dengan preferensi dan kebutuhan.

d. Amenitas: Terdiri atas amenitas pendukung untuk skywalk (lahan parkir, restoran/café dan toko oleh-oleh) dan amenitas pada skywalk (Ruang Terbuka Hijau, toilet, musholla, bangku, charging booth, penerangan, pos keamanan dan CCTV, pos informasi, Alat Pemadam Kebakaran/APAR, tempat sampah, dan tempat berteduh). Kondisi amenitas atau fasilitas ini cenderung kurang 
terpelihara, bahkan beberapa dalam kondisi rusak (APAR, tempat berteduh, pos keamanan, pos informasi) serta tidak aktif/terkunci (CCTV dan charging booth).

e. Ancillary: Organisasi pengurus atau pengelola Skywalk Teras Cihampelas tergabung dalam Forum Satuan Tugas Skywalk yang terdiri atas 1) Badan Pengelola Teras Cihampelas (BPTC) sebagai pengelola urusan fisik minor dan penengah antara PKL, masyarakat sekitar dan pemerintah, 2) Dinas Pekerjaan Umum (DPU) Kota Bandung sebagai pengelola urusan fisik major, 3) Dinas Koperasi dan UMKM Kota Bandung sebagai pengelola dan pembimbing PKL skywalk, serta 4) Dinas Kebudayaan dan Pariwisata yang seharusnya mengelola urusan promosi, atraksi wisata dan pelestarian budaya pada skywalk namun berdasarkan wawancara dan observasi tidak aktif dan tidak mempunyai data mengenai skywalk. BPTC mengeluhkan bahwa sering terjadi selisih pendapat dan kurangnya pemeliharaan pada fisik major. Dinas Pekerjaan Umum menyatakan bahwa selisih pendapat terjadi karena rumitnya birokrasi dan minimnya pendanaan untuk pengurusan infrastruktur. Para pengelola yang aktif menyatakan bahwa diperlukan pihak ketiga pengelolaan seperti Corporate Social Responsibility (CSR) untuk mendukung pengelolaan dan promosi dari skywalk namun belum terealisasi karena pandemi COVID-19.

Kuesioner ini dibagikan ke 100 pengunjung dengan kriteria pernah mengunjungi Skywalk Teras Cihampelas dalam kurun waktu 2 tahun terakhir. Kuesioner terbagi atas 4 bagian, yakni 1) Data Umum: Tujuan Kunjungan, 2) Kinerja Pengelolaan Komponen Wisata, serta 3) Profil dan Karakteristik Pengunjung. Dapat diketahui bahwa pengunjung kebanyakan berjenis kelamin perempuan (54 responden) dengan usia tergolong dalam kelompok umur produktif, yakni $15-25$ tahun (52 responden). Domisili responen dominan berasal dari area luar Kota Bandung (70 responden) dengan pekerjaan dominan adalah karyawan swasta (32 responden). Para pengunjung ini memakai kendaraan pribadi seperti motor atau mobil untuk mencapai Kawasan Cihampelas dan berwisata bersama keluarga (37 dan 35 responden). Para responden menyatakan bahwa sudah melakukan kunjungan sekitar $2-5$ kali berwisata ke Skywalk Teras Cihampelas (51 responden).

Motif kujungan dan aktivitas kebanyakan pengunjung skywalk adalah untuk rekreasi atau melihat pemandangan dengan 79 responden, dimana para pengunjung dominan datang pada sore hari (15.00 - 18.00 WIB) berdasarkan 48 responden. Rata-rata pengunjung menghabiskan waktu $20-45$ menit pada skywalk (39 responden), dimana kebanyakan melakukan mengeluarkan biaya berbelanja dengan total diatas $\mathrm{Rp} 50.000$,- (28 responden). Para pengunjung ini mengetahui informasi awal mengenai skywalk dari media sosial seperti Facebook, Twitter, Instagram, platform berita dan lainnya (46 responden).

Para responden kemudian menilai kinerja dari segi kemudahan, kondisi dan ketersediaan komponen wisata yang ada di Skywalk Teras Cihampelas yang terdiri dari atas 6 aspek, yakni aksesibilitas, atraksi, akomodasi, amenitas dan ancillary. Penilaian menggunakan angka $1-5$ dengan bobot skor 1 - sangat tidak baik (STB), skor 2 - tidak baik (TB), skor 3 - cukup (C), skor 4 - baik (B), dan skor 5 sangat baik (SB). Berikut adalah hasil jawaban responden terhadap kuesioner. Aspek yang memiliki nilai 1 dan 2 (STB dan TB) perlu dilakukan pemeliharaan, perbaikan atau penggantian dan nilai 3 (C) perlu dilakukan pemeliharaan dan peningkatan kualitas.

Tabel 2. Hasil Penilaian Komponen Wisata oleh Pengunjung

\begin{tabular}{llc}
\hline \multicolumn{1}{c}{ Cakupan } & Nilai Rata-Rata & Ket \\
\hline \multicolumn{1}{c}{ Aksesibilitas } & & \\
\hline Kemudahan sirkulasi pergerakan dari titik awal - titik akhir & 4 & $\mathrm{~B}$ \\
\hline Kondisi kenyamanan selama berjalan kaki di skywalk & 4 & $\mathrm{~B}$ \\
\hline Kondisi sirkulasi untuk lansia dan penyandang disabilitas & 2 & TB \\
\hline Posisi alat akses keluar-masuk skywalk & 4 & $\mathrm{~B}$ \\
\hline Bentuk dan keamanan penggunaan alat akses & 3 & $\mathrm{C}$ \\
\hline
\end{tabular}




\begin{tabular}{|c|c|c|}
\hline Cakupan & Nilai Rata-Rata & Ket \\
\hline Kondisi alat akses untuk lansia dan penyandang disabilitas & 2 & TB \\
\hline Kemudahan pencarian papan informasi & 4 & B \\
\hline Ketinggian papan informasi & 4 & B \\
\hline Kondisi dan kemudahan pemahaman informasi yang termuat & 4 & B \\
\hline \multicolumn{3}{|l|}{ Aktivitas dan Atraksi } \\
\hline Atraksi yang pernah dilakukan di skywalk & 2 & TB \\
\hline Kondisi atraksi yang tidak terjadwal & 2 & TB \\
\hline Keperluan penambahan atraksi pada skywalk & 5 & Sangat Perlu \\
\hline \multicolumn{3}{|l|}{ Akomodasi } \\
\hline Kemudahan pencarian penginapan disekitar skywalk & 5 & SB \\
\hline Kondisi atau kualitas penginapan disekitar skywalk & 5 & SB \\
\hline \multicolumn{3}{|l|}{ Amenitas } \\
\hline Tempat memarkir kendaraan & 2 & TB \\
\hline Restoran/café & 4 & $\mathrm{~B}$ \\
\hline Toko oleh-oleh & 4 & $\mathrm{~B}$ \\
\hline Ruang Terbuka Hijau / Taman & 3 & $\mathrm{C}$ \\
\hline Toilet & 2 & TB \\
\hline Musholla & 2 & TB \\
\hline Bangku & 3 & $\mathrm{C}$ \\
\hline Charging Booth & 3 & $\mathrm{C}$ \\
\hline Fasilitas Penerangan & 3 & C \\
\hline Fasilitas Pengamanan & 3 & $\mathrm{C}$ \\
\hline Pos Informasi & 3 & $\mathrm{C}$ \\
\hline Alat Pemadam Kebakaran & 2 & TB \\
\hline Tempat Pembuangan Sampah & 3 & $\mathrm{C}$ \\
\hline Tempat Berteduh & 3 & C \\
\hline Kebersihan, kecocokkan material, warna, aroma dan suasana fasilitas & 3 & C \\
\hline \multicolumn{3}{|l|}{$\begin{array}{ll} & \text { Ancillary }\end{array}$} \\
\hline Pemeliharaan kebersihan dan keindahan & 2 & TB \\
\hline Kualitas pelayanan PKL & 4 & $\mathrm{~B}$ \\
\hline Harga barang yang diperjualbelikan & 4 & $\mathrm{~B}$ \\
\hline Promosi skywalk & 2 & TB \\
\hline Kemudahan pencarian informasi skywalk terutama melalui online & 2 & TB \\
\hline Ketanggapan dan kerjasama antar pengelola & 2 & TB \\
\hline Penerimaan kritik dan saran & 3 & C \\
\hline Keefektifan pengadaan skywalk sebagai upaya pengurangan kemacetan & 3 & C \\
\hline
\end{tabular}

Sumber: Kuesioner Penilaian Komponen Wisata Skywalk Teras Cihampelas dari Pengunjung oleh Peneliti, 2021

\section{Analisis Evaluasi Kondisi Terhadap Standar Jalur Pejalan Kaki}

Evaluasi ini dilakukan untuk mengidentifikasi keadaan eksisting jika dibandingkan dengan teori standar yang berlaku dengan melakukan kegiatan skoring. Skoring dilakukan dengan menetapkan kriteria standar jalur pejalan kaki yang diadopsi dari Peraturan Menteri Pekerjaan Umum No. 03/PRT/M/2014 dan Planning and Designing for Pedestrians Model Guideline dari Community Design + Architecture, Inc. untuk San Diego's Regional Planning Agency (SANDAG) tahun 2002 yang sudah diolah untuk menyesuaikan dengan Skywalk Teras Cihampelas. Terdapat 6 aspek persyaratan standar pelayanan jalur pejalan kaki, yakni aksesibilitas, keselamatan, kenyamanan, keindahan, kemudahan, dan interaksi. Evaluasi ini dilakukan dengan pengambilan skoring berdasarkan observasi, skoring berdasarkan ahli dari akademisi dan skoring berdasarkan ahli dari pemerintahan. Peneliti dibantu oleh Julio Ustari Putra, ST., M.Han sebagai pelaku skoring ahli dari akademisi dan Melky Koswara, ST. dari Dinas Pekerjaan Umum Kota Bandung sebagai pelaku skoring ahli dari pemerintahan. Skoring dilakukan dengan memberi skor dengan keterangan skor 1 - Tidak Sesuai Standar (TSD), skor 2 Perlu Penyesuaian (PSD), skor 3 - Memenuhi Standar Minimum (C), skor 4 - Sesuai Standar (B), dan skor 5 - Sempurna/pertahankan (A). Berikut adalah hasil skoring untuk Skywalk Teras Cihampelas. 
Tabel 3. Hasil Skoring Kondisi Eksisting Terhadap Standar Jalur Pejalan Kaki

\begin{tabular}{|c|c|c|c|c|c|c|c|}
\hline \multirow[b]{2}{*}{ Aspek } & \multirow[b]{2}{*}{ Kriteria } & \multicolumn{3}{|c|}{ Hasil Skoring } & \multirow{2}{*}{$\begin{array}{c}\text { Skor } \\
\text { Rata- } \\
\text { rata }\end{array}$} & \multirow[b]{2}{*}{ Status } & \multirow[b]{2}{*}{ Kesimpulan } \\
\hline & & Observasi & Akademisi & Ahli & & & \\
\hline \multirow[b]{2}{*}{ Aksesibilitas } & $\begin{array}{l}\text { Dapat } \\
\text { dipergunakan } \\
\text { oleh semua } \\
\text { pejalan kaki } \\
\text { termasuk } \\
\text { disabilitas } \\
\end{array}$ & 3 & 3 & 2 & 3 & C & $\begin{array}{l}\text { JPK dapat digunakan oleh } \\
\text { orang kebanyakan namun } \\
\text { masih sulit digunakan lansia } \\
\text { dan penyandang disabilitas. }\end{array}$ \\
\hline & $\begin{array}{l}\text { Street furniture } \\
\text { dan vegetasi } \\
\text { yang ada } \\
\text { berguna } \\
\text { sebagai } \\
\text { penunjuk } \\
\text { arah/batas } \\
\end{array}$ & 4 & 3 & 4 & 4 & B & $\begin{array}{l}\text { Street furniture dan } \\
\text { vegetasi tidak mengganggu } \\
\text { JPK. Peletakan pada } \\
\text { beberapa lokasi } \\
\text { membentuk alur pejalan } \\
\text { kaki. }\end{array}$ \\
\hline \multirow{3}{*}{ Keselamatan } & $\begin{array}{l}\text { Pemisahan } \\
\text { ruang pejalan } \\
\text { kaki dengan } \\
\text { jalur ekonomi } \\
\text { perdagangan } \\
\text { serta street } \\
\text { furniture }\end{array}$ & 2 & 3 & 2 & 2 & PSD & $\begin{array}{l}\text { Ruang pejalan kaki tidak } \\
\text { terganggu dengan street } \\
\text { furniture tetapi terganggu } \\
\text { dengan jalur perdagangan. }\end{array}$ \\
\hline & $\begin{array}{l}\text { Terdapat area } \\
\text { atau fasilitas } \\
\text { untuk } \\
\text { pengamanan } \\
\text { dan keadaan } \\
\text { darurat } \\
\end{array}$ & 2 & 2 & 3 & 2 & PSD & $\begin{array}{l}\text { Fasilitas pengamanan dan } \\
\text { keadaan darurat yang ada } \\
\text { rusak \& tidak terdapat } \\
\text { assembly point, sehingga } \\
\text { diperlukan perbaikan dan } \\
\text { penyesuaian secepatnya. }\end{array}$ \\
\hline & $\begin{array}{l}\text { Vegetasi dan } \\
\text { street furniture } \\
\text { terletak pada } \\
\text { titik yang aman } \\
\text { dari tindakan } \\
\text { vandalisme } \\
\text { atau perusakan }\end{array}$ & 4 & 4 & 4 & 4 & B & $\begin{array}{l}\text { Terletak di ruang bebas } \\
\text { pejalan kaki, memiliki tinggi } \\
\text { aman sesuai standar namun } \\
\text { beberapa tidak dalam } \\
\text { kondisi yang baik (vegetasi } \\
\text { \& warning signage). }\end{array}$ \\
\hline \multirow[b]{3}{*}{ Kenyamanan } & $\begin{array}{l}\text { Jalur pejalan } \\
\text { kaki memiliki } \\
\text { lebar yang } \\
\text { nyaman }\end{array}$ & 4 & 4 & 4 & 4 & B & $\begin{array}{l}\text { Memiliki lebar efektif } 1,8 \text { - } 2 \\
\mathrm{~m} \text { tetapi jalur pejalan kaki } \\
\text { pada area perdagangan } \\
\text { tetap terganggu. }\end{array}$ \\
\hline & $\begin{array}{l}\text { Tingkat } \\
\text { kemiringan dan } \\
\text { permukaan } \\
\text { jalur pejalan } \\
\text { kaki yang baik }\end{array}$ & 4 & 4 & 4 & 4 & B & $\begin{array}{l}\text { Memiliki tingkat kemiringan } \\
\text { tidak lebih dari } 8 \% \text { tetapi } \\
\text { terdapat permukaan yang } \\
\text { licin, yakni keramik \& glass } \\
\text { block. }\end{array}$ \\
\hline & $\begin{array}{l}\text { Jalur memiliki } \\
\text { pelindung dari } \\
\text { cuaca } \\
\text { (shade/shelter) }\end{array}$ & 2 & 3 & 3 & 3 & C & $\begin{array}{l}\text { Terdapat peneduh berupa } \\
\text { pepohonan namun } \\
\text { dianggap tidak efektif oleh } \\
\text { PKL dan pengunjung. } \\
\text { Shelter instalasi bambu } \\
\text { sudah rusak. PKL akhirnya } \\
\text { memakai terpal tetapi tidak } \\
\text { cocok dengan lingkungan } \\
\text { dan mengganggu jalur } \\
\text { sirkulasi. }\end{array}$ \\
\hline Keindahan & $\begin{array}{l}\text { Desain } \\
\text { mewakili } \\
\text { karakteristik } \\
\text { lokal }\end{array}$ & 2 & 2 & 3 & 2 & PSD & $\begin{array}{l}\text { Patung karakter sebagai } \\
\text { desain muka bangunan } \\
\text { banyak dihilangkan. Desain } \\
\text { jembatan kurang }\end{array}$ \\
\hline
\end{tabular}




\begin{tabular}{|c|c|c|c|c|c|c|c|}
\hline \multirow[b]{2}{*}{ Aspek } & \multirow[b]{2}{*}{ Kriteria } & \multicolumn{3}{|c|}{ Hasil Skoring } & \multirow{2}{*}{$\begin{array}{c}\text { Skor } \\
\text { Rata- } \\
\text { rata }\end{array}$} & \multirow[b]{2}{*}{ Status } & \multirow[b]{2}{*}{ Kesimpulan } \\
\hline & & Observasi & Akademisi & Ahli & & & \\
\hline & lingkungan & & & & & & $\begin{array}{l}\text { mengangkat karakteristik } \\
\text { lingkungan dan tidak } \\
\text { memperhatikan histori } \\
\text { Kawasan Cihampelas. }\end{array}$ \\
\hline & $\begin{array}{l}\text { Terdapat } \\
\text { bangunan } \\
\text { aksesibel, } \\
\text { estetika ruang } \\
\text { dan kebersihan } \\
\text { terjaga }\end{array}$ & 3 & 3 & 3 & 3 & C & $\begin{array}{l}\text { Hanya terdapat } 1 \text { bangunan } \\
\text { yang dapat diakses dan } \\
\text { tidak selalu dalam keadaan } \\
\text { buka. Terdapat pengadaan } \\
\text { ruang terbuka hijau untuk } \\
\text { menyesuaikan dengan } \\
\text { lingkungan yang awalnya } \\
\text { banyak pepohonan. }\end{array}$ \\
\hline \multirow{2}{*}{ Kemudahan } & $\begin{array}{l}\text { Mempunyai } \\
\text { public } \\
\text { perimeter atau } \\
\text { dapat terlihat } \\
\text { dari komunitas } \\
\text { sekitar }\end{array}$ & 2 & 2 & 4 & 3 & C & $\begin{array}{l}\text { Mempunyai public } \\
\text { perimeter rendah (pintu } \\
\text { masuk terlihat namun } \\
\text { orang luar sulit melihat } \\
\text { kegiatan dalam skywalk) }\end{array}$ \\
\hline & $\begin{array}{l}\text { Efisiensi biaya } \\
\text { dan tenaga } \\
\text { untuk } \\
\text { penggunaan } \\
\text { jalur }\end{array}$ & 3 & 3 & 3 & 3 & C & $\begin{array}{l}\text { Tidak terdapat biaya/biaya } \\
\text { yang dikeluarkan sedikit } \\
\text { untuk pencapaian satu titik } \\
\text { ke titik lainnya dan } \\
\text { konektivitas rendah } \\
\text { terhadap wilayah sekitar }\end{array}$ \\
\hline \multirow{2}{*}{ Interaksi } & $\begin{array}{l}\text { Memiliki } \\
\text { tempat untuk } \\
\text { berinteraksi } \\
\text { sosial }\end{array}$ & 3 & 4 & 4 & 4 & B & $\begin{array}{l}\text { Skywalk memiliki berbagai } \\
\text { macam fasilitas untuk } \\
\text { berinteraksi dan menjadi } \\
\text { ruang publik, seperti } \\
\text { tempat duduk, balkon, kios } \\
\text { dan stage. }\end{array}$ \\
\hline & $\begin{array}{l}\text { Memiliki } \\
\text { fasilitas dan } \\
\text { atraksi } \\
\text { pelengkap } \\
\text { untuk } \\
\text { berinteraksi }\end{array}$ & 3 & 3 & 1 & 2 & PSD & $\begin{array}{l}\text { Terdapat atraksi namun } \\
\text { sudah lama tidak aktif } \\
\text { kembali dan diperlukan } \\
\text { atraksi baru. }\end{array}$ \\
\hline
\end{tabular}

03/PRT/M/2014 dan Pedestrian Model Guidelines, 2021

\section{Analisis Benchmarking / Best Practise}

The High Line, New York

The High Line adalah jembatan "elevated-park" yang dahulunya merupakan jembatan rel kereta penghubung antar wilayah untuk mengantarkan barang dan makanan sekitar tahun 1920-an. Jembatan rel ini beroperasi sampai tahun 1980 kemudian terabaikan dan direncanakan akan dihancurkan. Namun karena tingginya biaya untuk menghancurkan, pemerintah setempat memutuskan untuk mengubahfungsi jembatan tersebut sebagai upaya pembangunan berkelanjutan. Pada tahun 2014, sebuah organisasi non-profit bernama Friends of The High Line mengadakan kompetisi untuk mencari desainer guna revitalisasi yang akhirnya dimenangkan oleh James Corner Field Operations dan Diller Scofidio + Renfro.

Ide awal desain The High Line adalah "nature taking over the ruin" untuk mengabadikan masa-masa ketika jembatan terabaikan. Masih terdapat beberapa rel kereta yang dibiarkan agar dapat mengembalikan jembatan ke fungsi awalnya, tetapi terdapat juga sebuah jalan setapak menggunakan papan beton pracetak dengan sambungan terbuka untuk tempat tanaman tumbuh. Pengembangan jembatan dibagi atas 4 fase untuk tahun 2009, 2011, 2014 dan terakhir pada 2019. 
Pengembangan The High Line menggunakan biaya investasi New York sekitar \$115 juta USD (sekitar Rp 1.640.000.000.000,-). Keunggulan dari The High Line adalah konektivitas dan open space.
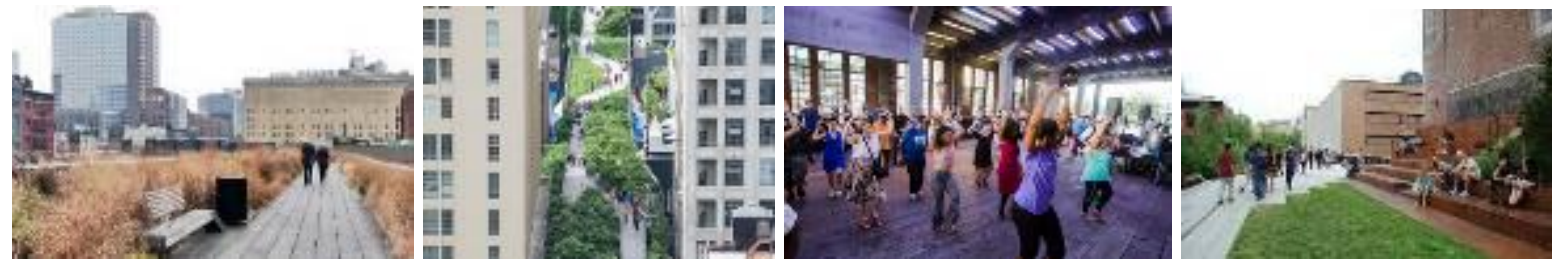

Gambar 5. The High Line, New York

Sumber: thehighline.org, 2019

\section{Seoullo 7017 Skypark, Korea Selatan}

Seoullo 7017 Skypark merupakan jembatan layang yang sebelumnya adalah jalan raya kemudian diubahfungsi menjadi taman layang di Korea Selatan. Makna dari nama jembatan ini adalah tahun infrastruktur dibuat (1970), tahun infrastruktur direvitalisasi (2017) dan karena jembatan ini menghubungkan 17 jalan di sekitar jembatan tersebut. Jembatan ini awalnya dianggap tidak layak setelah dilakukan evaluasi struktur dan akan dihancurkan, namun pada tahun 2014 pemerintah setempat memutuskan untuk memperkuat kembali struktur dan membuat jembatan sebagai "expanded green space" serta "human-oriented walkable city" dalam upaya pembangunan berkelanjutan dan membuat kawasan bernilai makin tinggi (Jackson, 2017).

Desain dari proyek Seoullo 7017 dilakukan dengan sistem kompetisi dan dimenangkan oleh Winny Maas (MVRDV) dari Netherlands. Konsep pengembangan Seoullo 7017 adalah sebagai library of plants', dimana terdapat sekitar \pm 24.000 tanaman yang ditanam pada 648 pot di sepanjang jembatan, disusun menurut urutan alfabet Korea (Hangeul). Seoullo 7017 Skypark dikelola langsung promosinya oleh Korea Toursim Organization (KTO) dan sering menjadi tempat shooting drama dan variety shows.
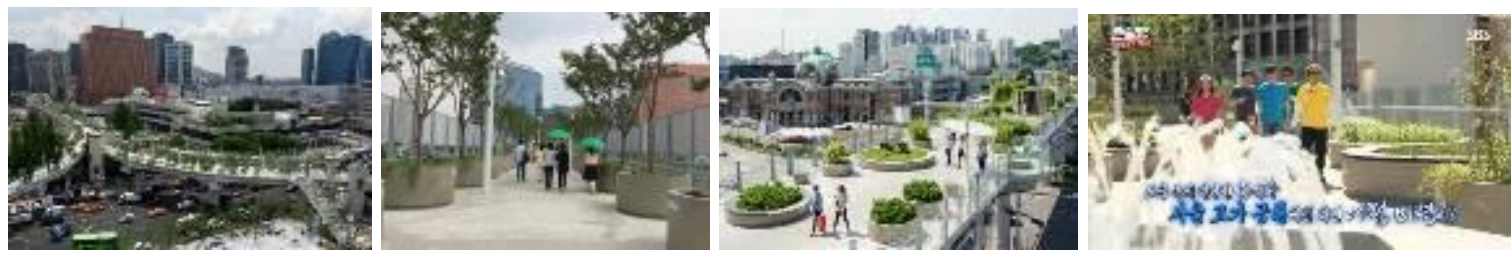

Gambar 6. Seoullo 7017 Skypark

Sumber: MVRDV dan Google Images, 2017

Tabel 4. Analisis Benchmarking The High Line - Seoullo 7017 - Skywalk Teras Cihampelas

\begin{tabular}{|c|c|c|c|}
\hline Komponen & The High Line & Seoullo 7017 Skypark & Skywalk Teras Cihampelas \\
\hline Aksesibilitas & $\begin{array}{l}\text { 1. Terdapat perbedaan yang jelas } \\
\text { untuk jalur pejalan kaki dengan } \\
\text { ruang lainnya sehingga pejalan } \\
\text { kaki merasakan kenyamanan } \\
\text { dengan tidak tercampur jalur lain. } \\
\text { 2. Dilengkapi dengan elevator (lift) } \\
\text { yang aktif, tangga, akses dari } \\
\text { gedung sekitar (passage) dan } \\
\text { ramp. Konektivitas dengan } \\
\text { gedung sekitar merupakan key } \\
\text { factor dari kesuksesan The High } \\
\text { Line. }\end{array}$ & $\begin{array}{l}\text { 1. Jalur pejalan kaki berbentuk } \\
\text { zig-zag terhalang pot-pot } \\
\text { sedang-besar, namun masih } \\
\text { terdapat jalur efektif pada sisi } \\
\text { tengah dengan lebar min } 1,8 \mathrm{~m} \\
\text { sehingga tidak terlalu terganggu. } \\
\text { 2. Seoullo } 7017 \text { lebih ramah } \\
\text { terhadap penyandang disabilitas } \\
\text { karena sudah tersedia braille } \\
\text { guiding blocks, speaker } \\
\text { pemandu dan interactive } \\
\text { signage. } \\
\text { 3. Dilengkapi dengan elevator, } \\
\text { escalator, akses dari gedung } \\
\text { sekitar (walkways) dan ramp. } \\
\text { Konektivitas dengan pusat }\end{array}$ & $\begin{array}{l}\text { 1. Jalur pejalan kaki memiliki } \\
\text { penghalang berupa kios PKL } \\
\text { yang diletakkan zig-zag secara } \\
\text { ekstrim. } r \text { Diperlukan } \\
\text { pembenahan dengan } \\
\text { penetapan zona jalur untuk } \\
\text { membedakan jalur pejalan kaki } \\
\text { dan jalur perdagangan. } \\
\text { 2. Beberapa fasilitas akses } \\
\text { seperti lift perlu perhatian } \\
\text { untuk segera diperbaiki dan } \\
\text { diaktifkan untuk wisatawan } \\
\text { lansia. } \\
\text { 3. Perlu pertimbangan untuk } \\
\text { pengajuan peningkatan } \\
\text { konektivitas ke beberapa }\end{array}$ \\
\hline
\end{tabular}




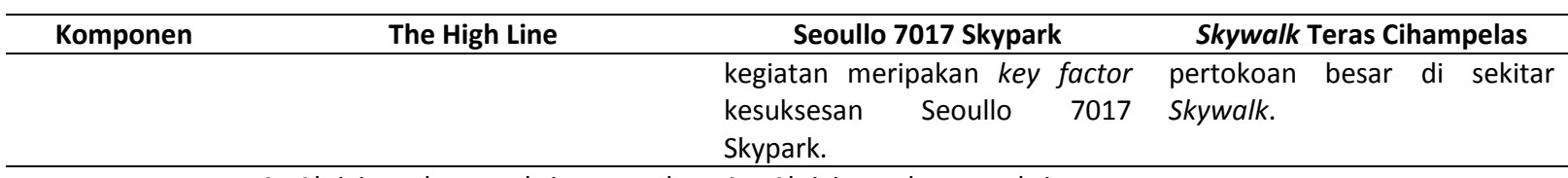

1. Aktivitas dan atraksi yang ada 1. Aktivitas dan atraksi yang pada The High Line ditawarkan Seoullo 7017 memanfaatkan berbagai fasilitas memanfaatkan tumbuhan yang yang sudah ada pada jembatan, ditanam sepanjang jembatan, seperti ruang duduk menjadi menjadikannya perpustakaan ruang diskusi, passage menjadi tumbuhan. mini-theater.

Aktivitas dan Atraksi
2. Atraksi yang diadakan juga merupakan atraksi family friendly, yakni melakukan kegiatan petualangan mengenal jembatan bagi anak-anak dan mengangkat seni budaya dengan bekerjasama dengan organisasi setempat.

3. Semua atraksi terdaftar dan terjadwal oleh pengelola The High Line.
2. Karena lokasi Seoullo 7017 yang dikelilingi spot bersejarah, banyak atraksi yang diadakan berkaitan dengan kebudayaan lokal seperti festival hari khusus, tari, parade dan body painting.

3. Barang yang dapat dibeli di Seoullo 7017 Skypark memiliki unsur kebudayaan Korea Selatan, mulai dari sovenir sampai kuliner khas Korea.
1. Fasilitas umum seperti toilet tidak terletak di atas jembatan, namun berada pada enterance.

2. Fasilitas yang ada mengangkat histori dari jembatan, seperti spur reserve dan authentic garden.

Amenitas

3. Fasilitas yang ada juga dimanfaatkan sebaik-baiknya, seperti perngubahan street passage menjadi mini-theater, restoran, atau lokasi untuk (penyewaan) private event.
1. Seoullo 7017 Skypark tidak memiliki toilet dan tempat sampah, sehingga pengunjung harus mencari fasilitas ini dengan gedung sekitarnya.

2. Fasilitas untuk lansia dan penyandang disabilitas diperhatikan dengan adanya CCTV, emergency bells dan speaker yang tersebar diseluruh area jembatan.

3. Fasilitas yang ada memanfaatkan teknologi, seperti penerangan yang dapat berganti sesuai hari peringatan dan interactive signage.

4. Terdapat inovasi untuk mengatasi masih kurangnya peneduhan karena tanaman yang masih muda, yakni pengadaan parasol rental (penyewaan payung untuk peneduh tambahan).

1. Perlu pengaturan berbagai kegiatan yang akan dilakukan akan lebih teratur dan memiliki strategi promosi yang tepat.

2. Kegiatan atraksi juga dapat ditambah dengan melihat benchmark, memanfaatkan lingkungan dan fasilitas yang sudah ada.

3. Perlu dilakukan pendekatan dan kerjasama dengan organisasi seni dan Dinas terkait untuk melakukan peningkatan atraksi.

1. Jika dibandingkan dengan benchmark, fasilitas yang ada pada Skywalk Teras Cihampelas cukup baik dan lengkap, salah satunya adalah adanya toilet dan tempat sampah. Namun masih sangat kurang dalam segi pemeliharaan kualitas fasilitas. 2. Fasilitas pada Skywalk Teras Cihampelas perlu dimanfaatkan sebaik-baiknya dengan mempelajari apa saja yang dilakukan pada benchmark, seperti pengadaan ruang diskusi, pojok kreatif, tempat permainan.

3. Fasilitas juga perlu inovasi untuk menyelesaikan problem tertentu, seperti mencontoh kasus peneduhan dengan penyewaan payung seperti di Seoullo 7017 dan perbaikan peneduh dengan material proper tapi ringan seperti payung untuk Masjid Nabawi atau dekorasi payung gantung..

1. Organisasi: Pengoperasian The High Line dikelola oleh Friends of The High Line bekerjasama dengan Departemen Taman dan Rekreasi Kota New York.

2. Manajemen dan SDM: Karena Friends of The High Line merupakan organisasi non-profit, pembiayaan operasi The High Line selain dari pemerintah dilakukan dengan mengumpulkan sponsor dan kontribusi masyarakat melalui: - Adopsi tanaman -
1. Organisasi: Dikembangkan desain dan revitalisasinya oleh MVRDV, bekerjasama dengan pemerintah kota, LSM lokal dan penasihat perencana kota untuk melestarikan jembatan bersejarah. Pengelolaan dipegang oleh Seoul Metropolitan Government.

2. Manajemen dan SDM: Pembiayaan pengelolaan selain dari pemerintah didapatkan melalui pembukaan adopsi
1. Organisasi: Kerjasama antar pengelolaan pada benchmark sangat baik, dimana terdapat Kerjasama antar pemerintahan setempat dan pengelola jembatannya. Sedangkan pada Skywalk Teras Cihampelas Kerjasama ini masih sangat minim dan cenderung lempar tanggung jawab.

2. Manajemen dan SDM: Pembiayaan pengelolaan 


\begin{tabular}{|c|c|c|c|}
\hline Komponen & $\begin{array}{l}\text { The High Line } \\
\end{array}$ & Seoullo 7017 Skypark & Skywalk Teras Cihampelas \\
\hline & $\begin{array}{l}\text { Donasi-Membership } \\
\text { 3. Promosi: Informasi dan donasi } \\
\text { The High Line dapat diakses } \\
\text { melalui sosial media dan website } \\
\text { thehighline.org yang dilakukan } \\
\text { langsung oleh Friends of The High } \\
\text { Line. }\end{array}$ & $\begin{array}{l}\text { tumbuhan. } \\
\text { 3.Promosi: Promosi Seoullo } \\
7017 \text { dilakukan oleh Korea } \\
\text { Tourism Organization } \\
\text { dengan membuat } \\
\text { khusus Seoullo } 7017 \text { Skypark } \\
\text { (namun hanya dapat diakses } \\
\text { pada Korea Selatan), sosial } \\
\text { media, pengadaan acara variety } \\
\text { shows Korea, dan tempat } \\
\text { shooting drama/film Korea. }\end{array}$ & 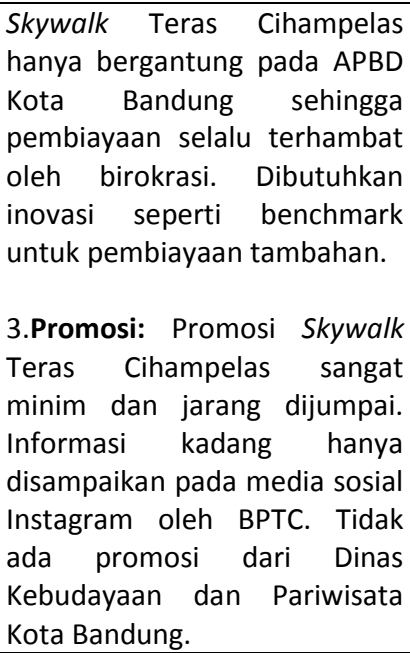 \\
\hline
\end{tabular}

Sumber: thehighline.org, mvrdv.nl, Google Earth dan Hasil Observasi Peneliti, 2021

\section{KESIMPULAN DAN REKOMENDASI}

\section{Kesimpulan}

Berdasarkan analisis yang telah dilakukan, masalah utama pada Skywalk Teras Cihampelas adalah pada komponen ancillary atau kepengurusan organisasi. Masih terdapat banyak masalah yang perlu diselesaikan dengan membutuhkan tindakan tegas Pemerintah Kota Bandung seperti penegasan pekerjaan (jobdesk) masing-masing dinas yang terkait, pembenahan berkas mengenai pengembangan skywalk, penetapan goal atau pencapaian bagi skywalk kedepannya dan pengaturan manajemen/birokrasi dari segi keuangan maupun Sumber Daya Manusia. Beberapa upaya memang telah dilakukan oleh pihak tertentu seperti BPTC dan Dinas Koperasi dan UMKM, tetapi apabila tidak terjadi komunikasi yang baik dengan Forum Satuan Tugas skywalk lainnya termasuk Pemerintah Kota Bandung, perbaikan akan sulit dilakukan dan tidak tepat sasaran. Apabila komponen ini sudah terselesaikan maka dapat mewujudkan perbaikan dan peningkatan pada komponen wisata lainnya. Aspek lainnya yang perlu penyesuaian kembali yakni menyangkut aspek keselamatan/keamanan pada komponen aksesibilitas dan amenitas, aspek keindahan desain serta penambahan karakteristik lingkungan untuk komponen amenitas dan atraksi, juga penambahan aspek interaksi untuk atraksi di Skywalk Teras Cihampelas.

\section{Rekomendasi}

Langkah yang dapat dilakukan untuk peningkatan pengelolaan Skywalk Teras Cihampelas perlu dijadwalkan atau ditargetkan dalam waktu tertentu yang dirangkum dalam action plan. Peneliti merekomendasikan untuk melakukan pembenahan dalam kurun waktu 3 tahun untuk meningkatkan pengelolaan sebagai destinasi wisata Kota Bandung. Pada tahun pertama dapat dilakukan peningkatan untuk aspek ancillary, yakni 1) Diskusi dan re-focusing jobdesk antar Forum Satuan Tugas Skywalk, 2) Peningkatan kerjasama kepada Dinas Daerah lainnya untuk pemeliharaan kebersihan, keindahan dan keamanan, 3) Pembentukan website skywalk dan pembenahan media sosial skywalk, 4) Pencarian sponsor (CSR) dan kerjasama dengan organisasi/komunitas setempat, 5) Perlakuan inovasi pembiayaan dengan pembukaan sistem volunteer, donasi dan adopsi fasilitas/tumbuhan. Setelah aspek ancillary selesai pada tahun pertama, dapat dilanjutkan pada tahun kedua untuk aspek amenitas dan aksesibilitas, yakni 1) Perbaikan dan pemeliharaan fasilitas (toilet, APAR, musholla, peneduhan), 2) Melakukan kerjasama penyediaan dan pengaturan lahan parkir, 3) Menambah transportasi umum untuk wisata ke skywalk, 4) Pembenahan tata letak Kios PKL dan jalur pejalan kaki, 4) Mengaktifkan kembali lift dan menambah fasilitas pemandu untuk lansia dan penyandang disabilitas. Kemudian langkah terakhir yang dapat dilakukan untuk tahun 
ketiga adalah pengadaan skywalk sebagai Creative Hub dan perencanaan kerjasama dengan komunitas lainnya untuk penambahan atraksi.

\section{REFERENSI}

Carr, S., Francis, M., Rivlin, L. G., \& Stone, A. M. (1992). Public Space. Cambridge University Press.

Community Design + Architecture, Inc. W-Trans. (2002). Planning and Designing for Pedestrians.

Fletcher, J., Fyall, A., Gilbert, D., \& Wanhill, S. (2018). Toursim, Principles and Practice. London: Logman.

Friends of the High Line. (2019). The High Line. Retrieved from https://www.thehighline.org/

Jackson, B. (2017, Mei 20). Seoullo 7017: Urban Asset or Vanity Project? Retrieved from koreaexpose: https://koreaexpose.com/seoullo-urban-asset-vanity-project/

Jianqiang, C. (2015). Assessing grade separation pedestrian systems: Planning, design and operation. United Kingdom: Macmillan Publishers.

Kementerian Pekerjaan Umum dan Penataan Ruang. (2014). Peraturan Menteri Pekerjaan Umum No. 03.PRT/M/2014. Pedoman Perencanaan, Penyediaan, dan Pemanfaatan Prasarana dan Sarana Jaringan Pejalan Kaki di Kawasan Perkotaan.

MVRDV. (2017). Seoullo 7017 Skygarden. Retrieved from https://www.mvrdv.nl/projects/208/seoullo-7017-skygarden

Pemerintah Daerah Provinsi Jawa Barat. (2017). Skywalk Cihampelas Destinasi Wisata Terpopuler. Retrieved from jabarprov.go.id: https://jabarprov.go.id/index.php/news/23938/Skywalk_Cihampelas_Kandidat_Destinasi_Wi sata_Terpopuler

Pemerintah Daerah Kota Bandung. (2013). Peraturan Daerah Kota Bandung No. 1. Rencana Induk Pembangunan Kepariwisataan Daerah tahun 2012 - 2025.

Pemerintah Daerah Kota Bandung. (2014). Peraturan Daerah Kota Bandung No. 3. Rencana Pembangunan Jangka Menengah Daerah (RPJMD) Tahun 2013 - 2018.

Permana, C. (2019, Juli 18). Teras Cihampelas Kian Sepi, Jumlah Kios yang Berjualan Tersisa Setengah, Berharap Solusi Pemerintah. (T. Ismail, Editor) Retrieved from TribunJabar.id: https://jabar.tribunnews.com/2019/07/18/teras-cihampelas-kian-sepi-jumlah-kios-yangberjualan-tersisa-setengah-berharap-solusi-pemerintah 